\title{
Study of Request Strategies Employed By Libyan and Malay POSTGRADUATE Students at USM
}

\author{
Awad Mohamed S Youssef \\ School of Educational of Studies, Universiti Sains Malaysia, \\ 11800 Penang, Malaysia
}

Tel: 006-173585612,E-mail: ayai_awead@yahoo.com

Accepted: March 6, 2012 Published: April 14, 2012

Doi:10.5296/ijld.v2i2.1631ＵRL: http://dx.doi.org/10.5296/ijld.v2i2.1631

\begin{abstract}
There has been considerable attention from the cross-cultural pragmatics literature towards the various strategies speakers use when performing the requesting speech act. Speech acts are often used when communicating verbally in either the first language or a second language.

This paper presents a study into the similarities and differences in the request strategies by Malaysian and Libyan postgraduate students at USM. The study majorly uses information from existing literature on what other people have written on this topic. The study findings will give new insights to the directness and requesting behaviors within Libyan and Malaysian students and the challenges of cross-linguistic and cross-cultural communication.

This study has cultural implications such as awareness of the request strategies used in one culture compared to another culture. This study tackles the ability of Libyan and Malay learners to apply requests in English. Furthermore, this study attempts to provide explanations for pragmatic errors that Libyan and Malay learners may perform.
\end{abstract}

Keywords: Cross-Cultural, Strategies, Modifications, Linguistic.

\subsection{Introduction}

There has been considerable attention from the cross-cultural pragmatics literature towards the various strategies speakers use when performing the requesting speech act. This is as a result of the extent of imposition that requesting has cross-gender and cross-linguistic/cultural variation in use and interpretation. The relevance of pragmatics has gained interest of both socio-and applied linguists as reflected in the literature on communication strategies related to a number of empirical studies regarding speech act behaviors. (Rintell, 1981; Blum-Kulka, 1982: 1983; El-Shazly, 1993; Alammar, 2000). This study would shed light on the similarities and differences in request strategies employed by 
Libyan and Malay students. The study has cultural implications such as awareness of the request strategies used in one culture compared to another culture. It tackles the ability of Libyan and Malay learners to apply requests in English. Furthermore, this study attempts to provide explanations for pragmatic errors that Libyan and Malay learners may perform.

\subsection{Literature Review}

Speech acts are often used when communicating verbally in either the first language or a second language. In other words, a very important part of pragmatics in any language consists of speech acts. Austin (1962) suggests speech acts as doing things by words such as asking, thanking, ordering, promising, requesting, warning, challenging, threatening, and so on. Many people who communicate across linguistic and cultural boundaries have experienced communication breakdown with interlocutors who are from different first language backgrounds or who speak different varieties of a language. Sociolinguists recognize that such intercultural miscommunication is partly due to different value systems that underlie each first language speaker's culture group (Damen, 2007). Understanding the motives behind utterances is often crucial to successful communication. Searle (1975) argues that the relationship between the surface form of an utterance and its underlying purpose isn't always straightforward.

\subsection{Request}

The concept of request is important because it helps us to understand the way in which a certain society is maintained through individuals' everyday conduct. In daily communication, we always ask people to do things. We may ask a person to give us something, or ask the person to do some actions. These are all requests. Request refers inclusively to an utterance that is intended to indicate the speaker's desire to regulate the behavior of the listener that is, to get the listener to do something. (Becker, 1982, as cited in Achiba, 2003). A request is made when a speaker asks a hearer to do something. In other words the speaker is imposing on the hearer. The hearer has to pay the cost of carrying out the request, and the speaker usually gains the profit out of it.

Kahraman defines request expressions as " asking a hearer to do or to quit doing something for a speaker or someone else who stands in relation to the speaker, hence the hearer will physically or psychologically have made efforts and the speaker will have gained benefits". In day-to-day interactions between the members of a community, each action is performed in order to maintain someone's "face" and to avoid losing "face". Since a requester appeals to the requestee's assistance, he/she is potentially threatening the requestee's "negative face

There are three situational variables which affect a speaker's imposition on a hearer: 1) Necessity of the request (how badly a speaker needs to impose on a hearer; greater necessity makes imposition smaller) 2) Ease of carrying out the request (the easier a request is to carry out, the less is the imposition) 3) Cultural differences (people with different cultural background perceive the same request as having different imposition) (Kitao, 1988). 


\subsection{Speech Act Theory}

The British philosopher, J.L Austin developed the Speech Act theory in 1962, but later it was modified by Searle (1969). There are many kinds of acts associated with the speaker's utterances in a typical speech situation (Searle, 1972). Searle (1972) calls production of linguistic communication as 'a speech act'. Blum-Kulka, House and Kasper (1989) consider the study of speech acts as being a central concern of pragmatics, especially in cross-cultural pragmatics. According to Searle (1969), when a person makes an utterance, it is primarily to perform a speech act. Each speech act has at least two parts: (1) Locutionary Acts, the act of speaking or creating an utterance, and (2) Illocutionary Acts, the act that is performed through the force of the utterance, such as apologizing, stating, ordering, etc. A speech act may also have a third aspect, Perlocutionary Acts, the act of evoking some effects on the audience through and limited by the circumstances of a specific illocutionary act.

Searle (1973) argues that all speech acts are governed by constitutive rules that define the conditions which must exist in order for the speech acts to take place. The knowledge of these rules is part of what is called " "linguistic competence". Searle (1983) proposes that speech acts such as " requests" are governed by four types of felicity conditions. These are preparatory conditions, sincerity conditions, prepositional content conditions (future act of hearer) and essential conditions ( attempts to persuade the hearer to do the act ). Some speech acts address the hearer directly, but most of them are indirect. Speakers try to resort to indirectness to attain some politeness level. The speech act of requesting has been used widely in interlanguage pragmatics research. Considering Searle's calssification of illocutionary acts as mentioned above, the requests fall under the second category, that of directives, which has been regarded as " attempts by the speaker to get the hearer to do something" (Searle, 1979)

\subsection{Politeness Theory}

Being polite is a complicated process in any language. It is indeed very difficult to learn to be polite because it involves understanding not just the language, but also the social and cultural values of the community. Brown and Levinson (1987) developed a theory of politeness to explain the nature of politeness phenomena in language. The description and conceptualization of politeness across languages and cultures have been the interest of Brown and Levinson (1978, 1987). Their model of politeness could well be described as the most influential theory of politeness, which is still the most prominent in the field of linguistic politeness.

At the core of Brown and Levinson's theory is the notion of 'face' which is a property that all humans have and that is broadly "linked to a person's public self-esteem or self-image which can be lost, maintained, or enhanced, and must be constantly attended to in interaction" (Brown \& Levinson, 1987). Brown and Levinson adopted Goffman's concept of 'face' as "the positive social value a person effectively claims for himself by the line others assume he has taken during a particular contact" (Goffman, 1967), In addition, they extended Goffman's notion of 'face' into 'positive face' and 'negative face' according to interactants' wants. Positive face refers to the person's need to be accepted and liked by others, and his/her need to feel that his/her social group shares a common goal. 'Positive Politeness', therefore, orients to preserving and satisfying the positive face of people. When we use positive politeness we use 
speech strategies that emphasize our solidarity with the hearer, such as informal pronunciation, shared dialect or slang expressions, nicknames, more frequent reference to speakers and hearers as 'we' and requests which are less indirect (Peccei, 1999). Negative face, on the other hand, refers to the person's right to freedom of action and his/her need not to be imposed on by others. Therefore, 'negative politeness' orients to preserving and satisfying the negative face of people.

In their theory, Brown and Levinson argue, "certain acts intrinsically threaten face because by their nature they run contrary to face wants of the addressee and/or of the speaker" (Brown \& Levinson, 1987). By 'act', they have in mind what is intended to be done by a verbal or non-verbal communication, just as one or more 'speech acts' can be assigned to an utterance. They call such acts Face Threatening Acts (FTAs) and they make distinction between acts that threaten negative face and those that threaten positive face. FTAs that threaten positive face include such acts as orders, requests, suggestions, advices, warnings, offers and promises. On the other hand, FTAs that threaten negative face include such acts as disapprovals, criticisms, complaints, accusations, insults, contradictions, and interruptions. Brown and Levinson draw attention to an overlap in their classification of FTAs because some FTAs intrinsically threaten both negative and positive face (e.g., complaints, interruptions, threats, strong expressions of emotion, and requests for personal information (Brown \& Levinson, 1987).

Determining the level of politeness that the speaker employs in doing a FTA, as Brown and Levinson (1987) argue depends on three sociological variables. These variables are involved in the assessment of the seriousness of a FTA in many and perhaps all cultures. These are: (a) the 'social distance' (D) between the speaker and the hearer; (b) the 'relative power' (P) of the hearer over the speaker; and (c) the absolute ranking of imposition $(\mathrm{R})$ in the particular culture. Politeness in request is a communication strategy a speaker uses to achieve both goals at the same time. The speaker chooses the level of politeness based on the relative imposition involved in the request. Because requests are essentially discourteous, achieving a request may damage the relationship between the people concerned (Leech, 1983). Politeness, therefore, is an important issue in making requests. Making request more polite decreases the imposition involved and helps maintain the relationship between a speaker and a hearer.

\subsection{Statement of the Problem}

Interlanguage pragmatics is concerned with second language learners' acquisition and development of pragmatic competence in their second language (Blum-Kulka et al., 1989). It is very crucial to consider how non-native language users realize speech acts in order to discover how learners do things with words in a second language. Numerous interlanguage pragmatics studies have investigated the performance of nonnative speakers of different languages. However, studies that investigate the performance of Libyan and Malay learners of English are small in number. It is the lack of such studies that presents a need for the current study, which considers the linguistic mitigating options that Libyan and Malay learners use when making requests in the target language.

When making a request, the speaker expresses a desire that the hearer does an action. The hearer is, therefore, asked to do something, which is mainly for the benefit of the speaker. Requests, then, need to be carefully formulated in order to attain compliance of the hearer and 
fulfillment of the speaker's desire. Requests can be face-threatening acts, which call for considerable expertise on the part of the learner. Requests may differ crossculturally and linguistically since the way they are realized in one culture might not be appropriate in another. Therefore, there is a need to analyze request strategies between different cultures. This study tries to analyze the request strategies used by Libyan and Malaysian students.

\subsection{Methodology}

The scope of this study has managed to harmonize perspectives of different authors, and come up with conclusive ideas concerning request behaviors among the Malaysian and Libyan postgraduate students in USM. The extent of research done earlier by many researchers makes it reliable to use the already documented and peer reviewed sources. The research study focuses on the similarities and differences in the request strategies employed by Malaysian and Libyan postgraduate students in USM. The information was obtained majorly from secondary sources. This involved collation and synthesis of already existing research. The entire process of information search started from articulation of working plan. Therefore, the study was executed in a sequential manner with the information bearing similar perspective being grouped together.

Data used in this study are from existing literature on natural conversations and role-play. The secondary sources materials used included books and articles found in journals. In addition, there was an extensive online research via the internet. Various websites with the relevant information were visited. The information from all these secondary sources were then summarized and compiled.

\subsection{Results and Discussion}

\subsection{Openers}

Openers alert the attention of the hearer to ensure a speech act. Both groups do not utilize openers. There are high chances that in actual-talk-interactions, speakers in either group make little effort to begin a conversation in conversing with the addressee having an acquaintance with a junior power position. However, the speakers utilized openers in role-plays (Searle, 1979).

\subsubsection{Overall Findings}

In role-plays, the two groups indicated a strong trend to opt for head acts that are query preparatory-conventionally indirect, whereas in natural conversations, the strategies that employed in many occasions were head act.

1. In role-plays, Malaysian speakers utilize many honorific devices, but in Libya, there were none. None of the Malaysian speakers uses lexical modification while engaging in natural conversations, whereas Libyan speakers present a wide range of lexical modifications. The two groups use syntactic downgraders.

2. In role-plays, Malaysian speakers make more varied utilization of external modifications as opposed to Libyan speakers, while in natural conversations, all the groups showed far less 
utilization of external modifications. Libyan speakers make some utilization of external upgraders.

3. Both groups utilized openers in role-plays only. Malaysian speakers prefer openers with neutrals, an alteration from the forms utilized in some situations; Libyan speakers prefer openers with upgrading functions, with consistency with their usage (Achiba, 2003).

\subsection{Head Acts}

In making requests to familiar junior students, Malaysian speakers use the suggestory formulae $(33 \%)$ and query preparatory $(67 \%)$ which are conventionally indirect strategies. Likewise, Libyan participants have a tendency of using the query preparatory (75\%). They also prefer the mood derivable-imperative (25\%) which is a direct head act (Kahraman, 2007).

\subsection{Internal Modifications (Lexical)}

Malaysian students have a tendency of employing an understater (43\%), as an internal modification. Other strategies that are popular among them include appealers, subjectivizers, hedges, hesitation markers, and delimiters at $14 \%$ for each item.

Libyan speakers also use the understater (33\%) but at a lower rate as compared to Malaysian speakers. Libyan requests apply understaters, downtoners and honorific devices at equal proportions of $(33 \%)$.

\subsection{External Modifications}

As an external modification, Malaysian speakers strongly prefer the sweetener (42\%). Their next choice was between disarmers and grounders, at about $17 \%$ each.

\subsection{Internal Modifications (Syntactic Downgraders)}

Both groups of students make much utilization of interrogatives: $86 \%$ of Malaysian requests and $100 \%$ of Libyan. Malaysian requests also consist of conditionals as syntactic downgraders.

\subsection{Internal modifications (syntactic downgraders)}

Both groups of students make much utilization of interrogatives: $86 \%$ of Malaysian requests and $100 \%$ of Libyan. Malaysian requests also consist of conditionals as syntactic downgraders

\subsection{External Modifications (Supportive Moves)}

Malaysian students have a more varied use of external modifications as compared to Libyan students. Malaysian speakers frequently employ the grounder $(62 \%)$ and the utilization of a cost minimize (15\%). On the contrary, Libyan requests consist of the cost minimize use at a higher frequency of $60 \%$ but the use of grounders is lower (20\%) (Searle, 1979).

\subsection{Natural Conversations versus Role-Plays}

Malaysian speakers do not use hints in role-plays, but they do so in natural conversations. A prominent feature about Malaysian natural conversations is the preference to utilization of mood deliverable-direct head acts (61\%) to up to 3 times more than the query 
preparatory (Damen, 1998). There are two reasons that explain the query preparatory domination in role-plays and the mood derivable-imperative domination in natural conversations. a) There are chances that the speakers in role-plays may employ well-mannered behavior thus affecting the setting. b) There were requestive impositions in role-play situations than in natural conversations, which might have left the participants employing more indirect head acts in their responses to reduce their imposition requests (Goffman, 1967). There was relatively lower imposition in natural conversations because there was a lesser need to reduce imposition requests making the speakers prefers direct head acts (Peccei, 1999).

The outstanding difference between role-plays and natural conversations is the use of mood derivable-imperative. In role-plays, the addition of polite markers manipulated the mood derivable while bare imperatives manipulated the natural conversations. This may be due to the difference between natural and informal settings as well as low and high imposition levels in natural conversations and role-plays respectivel (Becker \& Achiba, 2003).

\subsection{Patterns in the Request Strategy Use}

Both Malaysian and Libyan students use direct request strategies largely in natural conversations than role-plays. In role-plays, both groups use more direct head acts while in natural conversations, they use more indirect head acts.

There is a distinct use of honorific/politeness among the Libyans than Malaysians (Brown \& Levinson, 1978: 1987). On average, Malaysians use more indirect head acts while the Libyans use indirect and direct head acts at equal proportions. This shows that Malaysians in role-plays pay more attention when observed than Libyans do (Leech, 1983).

Both groups use the same external modifiers consisting of preparators, sweeteners, cost minimizers and grounders. Both groups mostly favor the grounders. Malaysian students employ fewer internal modifications and more external formulae than Libyan students to enhance request efficiency do. Malaysian students prefer the opener with neutrals while the Libyans prefer openers with an upgrading function (Austin, 1962).

\subsection{Conclusion}

This study on the linguistic behavior of request making among the Malaysian and Libyan postgraduate students gives a different dimension in the study of requests of speech acts, because it evades form the western language patterns. The study investigates the similarities and differences in request strategies employed by Libyan and Malay postgraduate students at USM. The findings give new insights to the directness and requesting behaviors within Libyan and Malaysian students and the challenges of cross-linguistic and cross-cultural communication. 


\section{References}

AL-Ammar, M. (2000). The Linguistic Strategies and Realizations of Request Behaviour in Spoken English and Arabic among Saudi Female English Majors at Riyadh College of Arts: Unpublished M.A. Thesis. Riyadh: King Saud University.

Austin, J. (1962). How To Do Things with Words. Oxford: Oxford University Press.

Achiba, M. (2003). Learning to Request in a Second Language: a Study of Child Interlanguage Pragmatics. N.Y.: Multilingual

Brown P. and Levinson S. (1978). Universals in language usage: Politeness phenomena. In: Goody E. Questions and politeness. Cambridge: Cambridge University Press.

Brown P. and Levinson S. (1987). Some universals in language usage Cambridge: Cambridge University Press.

Blum-Kulka S. (1982). Learning to say what you mean in a second language: study of the speech act performance of learners of Hebrew as a second language. Applied Linguistics 3(1), 29-60

Blum-Kulka S. (1983). Interpreting and performing speech acts in a second language A cross-cultural study of Hebrew and English. In Wolfson N. and Judd E. eds. Sociolinguistics and language acquisition. MA: Newbury House pp. 36-55

Becker\& Achiba, M. (2003). Learning to Request in a Second Language: a Study of Child Interlanguage Pragmatics. N.Y.: Multilingual Matters.

Damen, L. (1998). Cultural learning: The fifth dimension in the language classroom. Reading, MA: Addison-Wesley.

EL-Shazly, A. (1993). Requesting Strategies in American English, Egyptian Arabic and English as Spoken by Egyptian Second Language Learners. Unpublished M.A. Thesis Cairo: American University.

Goffman E. (1967). Interaction ritual: Essays on face to face behavior. Garden City, New York; Anchor Books

Kahraman, B. (2007) The use of request expressions by Turkish learners of Japanese. Journal of Theory and Practice in Education, (1), 3. 122-138.

Leech, G. N. (1983). Principles of pragmatics. London: Longman.

Peccei J. (1999). Pragmatics. London: Routtedge.

Rintell, E. (1981)." Getting your Speech Act Together: The Pragmatic Ability of Second Language Learners." A Working Paper on Bilingualism. The TESOL Convention: Washington D.C.

Searle, J. (1975). 'Indirect Speech Acts', in Peter Cole and Jerry L. Morgan (eds), Syntax and Semantics (3): Speech Acts, Academic Press, pp. 59-82. 